\title{
Proceeding
}

6th INSHS International Christmas Sport Scientific Conference, 11-14 December 2011. International Network of Sport and

Health Science. Szombathely, Hungary

\section{Does limited gear ratio driven higher training cadence in junior cycling reflect in maximum effort sprint?}

\author{
INDREK RANNAMA , KRISTJAN PORT, BORISS BAZANOV \\ Institute of health Sciences and Sport, Tallinn University, Estonia
}

\begin{abstract}
Rannama I, Port K, Bazanov B. Does limited gear ratio driven higher training cadence in junior cycling reflect in maximum effort sprint?. J. Hum. Sport Exerc. Vol. 7, No. Proc1, pp. S85-S90, 2012. Maximum gears for youth category riders are limited. As a result, youth category riders are regularly compelled to ride in a high cadence regime. The aim of this study was to investigate if regular work at high cadence regime due to limited transmission in youth category riders reflects in effectual cadence at the point of maximal power generation during the 10 second sprint effort. 24 junior and youth national team cyclist's average maximal peak power at various cadence regimes was registered on Cyclus-2 ergometer using cyclists own bikes. Effectual cadence at the point of maximal power generation (group average $113.9 \pm 10.6 \mathrm{rpm}$ ) is similar to the values of professional road cyclist during the last $200 \mathrm{~m}$ sprinting to finish where 10 second average cadence is $109.9 \pm 5.3 \mathrm{rpm}$ and highest average cadence is $117.6 \pm 6.1 \mathrm{rpm}$. The premise that regular work at high cadence regime due to limited transmission in youth category riders reflects in effectual cadence at the point of maximal power generation during the 10 second sprint effort was not corroborated. Key words: CYCLUS-2 ERGOMETER, MAXIMAL POWER, ISOKINETIC, YOUTH CATEGORY.
\end{abstract}

\footnotetext{
Corresponding author. Institute of health Sciences and Sport, Tallinn University, Tondi 55. 11316 Tallinn. Estonia.

E-mail: rannama@tlu.ee

6th INSHS International Christmas Sport Scientific Conference, 11-14 December 2011. International Network of Sport and Health Science. Szombathely, Hungary

JOURNAL OF HUMAN SPORT \& EXERCISE ISSN 1988-5202

(c) Faculty of Education. University of Alicante

doi:10.4100/jhse.2012.7.Proc1.10
} 


\section{INTRODUCTION}

In comparison with sports that utilise cyclic leg motion like running, bicycle gears provide flexibility to vary the speed of leg motion (rate at which a cyclist is turning the pedals or the number of revolutions of the crankset per minute, i.e. cadence) in comparison to overall speed of forward motion relative to ground. It is well known that mechanical power output in cycling depends on pedalling rate. Cyclists vary in a preferred cadence at which they feel most comfortable, hinting on individual balance between sensations and merging of diverse functional abilities like strength, endurance and coordination of individual muscles etc. Research in cycling has had a long time interest in search for optimum cadence that provides a rationale both for training and competing.

Evidence based (optimal energy utilisation, motor activation and efficiency of force transfer to pedals) recommendation postulates that for a well-trained athlete cadence at low to moderate power output should be between 90 and 105 rpm (Faria et al., 1982; Marsh \& Martin, 1993; Neptune \& Hull, 1999). With increasing power output the cadence shifts upwards (Coast \& Welch, 1985; Neptune \& Hull, 1999). The maximal peak power output during $10 \mathrm{~s}$ sprints have higher values in pedaling rates $100 \mathrm{rpm}$ and $120 \mathrm{rpm}$ and is lower in cadences 60, 80 and $140 \mathrm{rpm}$ (Zoladz et al., 2000). Van Soest and Casius (2000) find in musculoskeletal modelling that best cadence to achieve short time maximum power is near $120 \mathrm{rpm}$.

Evidence shows that during trek competitions world top sprinters attain maximum power output at pedalling rate near $129 \pm 9$ rpm (Dorel et al., 2005; Gardner et al., 2007). We have previously measured that during professional road cycling events with large group finish mainly dominated by sprinters the average of the complete finishing effort cadence was $109.9 \pm 5.3 \mathrm{rpm}$ and average of the highest cadence was $117.6 \pm 6.1$ rpm. Small group finishing that consists mainly of non-sprinters corresponding cadences were $95.9 \pm 6.4$ $\mathrm{rpm}$ and 101.0 $\pm 7.4 \mathrm{rpm}$ (unpublished data).

However, it is speculated that the optimal pedalling rate is not uniquely specified by the power-velocity relationship of muscle (Van Soest \& Casius, 2000). Hintzy et al. (1999) reported a positive relationship ( $r=$ 0.75 ) between the energetically optimal cadence and the cadence at which short-term power output was maximized. It is suggested that activation dynamics plays a large role in determining the optimal pedalling rate. One can see, that cadence at highest power output may also depend on muscle composition defined as a relative share of fast and slow twitch fibres (Ahlquist et al., 1992). Authors showed that the force demands of a task, rather than the velocity of contraction, determines the type of muscle fibres recruited. Cyclists who have higher ratio of Type-l, slow twitch fibres use at low to moderate power output cadence that is only slightly below cadence they show at their maximal power output effort. Athletes with lower relative share of Type-I fibres, demonstrated substantial divergence from cadence at low to moderate power output toward maximal effort. It has also been shown that share of slow twitch fibres in muscle composition to be in negative $(r=-0.81)$ correlation with cadence at maximum power output effort (Hansen et al., 2002). This leads to the findings of Umberger et al. (2006) who declare that the fundamental muscle properties determining the energetic of pedaling, rather than experience or training history. In contrast, Coast and Welch (1985) have suggested that during training cyclists adapt to become more efficient at pedaling, often with the adoption of a relatively high cadence.

According to the various national cycling and Union Cycliste Internationale (UCl) rules the maximum gears for youth category riders are limited defined as the amount the bike moves forward for every crank revolution known as gear roll out. As a result, youth category riders are regularly compelled to ride in a high cadence regime well above $100 \mathrm{rpm}$. At this point it is not known if the high cadence training and competing 
reflects in the power generation at the finishing sprint in youth category riders. More precisely the question is, if habituated work at high cadence reflects in effectual cadence at the point of maximal power generation during the 10 second sprint effort.

\section{MATERIAL AND METHODS}

The study participants were 12 national junior (U18) and 12 youth (U16) male Estonian road cycling team members. All cyclists went through anthropometrical measurements. The subjects characteristics were as follows (mean $\pm \mathrm{SD}$ ): age $16.6 \pm 1.1$ years, height $1.78 \pm 0.07 \mathrm{~m}$, and mass $67.7 \pm 8.7 \mathrm{~kg}$. All cyclists had at least 2 years cycling training and competition experience.

Experimental tests were performed on electrically braked research grade cycling ergometer platform Cyclus 2 (www.cyclus2.de) that allows usage of athlete's bike with individually adjusted and familiar fitting for best match with real life. After 20 minute warm-up three separate bouts of sprint efforts with 4 minute rest periods in isokinetic mode were conducted. Four minute rest is shown to be sufficient for recovery (Billaut et al., 2003). In isokinetic mode system varies applied force to keep the muscle contraction speed constant. For the testing three target cadences were set of $100 \mathrm{rpm}, 120 \mathrm{rpm}$ and $140 \mathrm{rpm}$ accordingly, the ergometer allows little variance $( \pm 3 \mathrm{rpm})$ in pre set cadence. All tests were conducted in sitting position hands gripping on the drops.

From each cadence level test the absolute and relative (power per $\mathrm{kg}$ of body weight) maximal peak and 10 seconds average power were detected. Also actual peak and 10 seconds average cadence of all subjects were registered. Mean values were computed for all cyclist's group ( $\mathrm{N}=24)$ and for U16 $(\mathrm{N}=12)$ and U18 $(\mathrm{N}=12)$ groups separately.

Data were expressed as mean \pm standard deviation (SD). All the data was tested for their normal distribution (Kolmogorov-Smirnov test). A Student's t-test for paired data was applied to compare maximal peak power and 10 second average power values of different cadence tests. One-way ANOVA was used to assess the differences of power and effectual cadence values between age groups. Relationships between cadence and power variables were examined by Pearson product-moment correlation. Significance level was set at $p<0.05$.

\section{RESULTS}

Junior and youth national team cyclist's average maximal peak power during all three tests (best attained power) was $999.2 \pm 231.6 \mathrm{~W}$ and 10 second average was $868.0 \pm 181.3 \mathrm{~W}$. Per $\mathrm{kg}$ of body weight the best attained power was $14.4 \pm 2.4$ and $12.8 \pm 1.8 \mathrm{~W} / \mathrm{kg}$ correspondingly. Comparison of the power at three different cadences revealed that at cadences of $100 \mathrm{rpm}$ (peak $958.5 \pm 195.0 \mathrm{~W} ; 10 \mathrm{sec} 840 \pm 166.7 \mathrm{~W}$ ) and $120 \mathrm{rpm}$ (peak $980 \pm 252.2 \mathrm{~W} ; 848.9 \pm 197.5 \mathrm{~W}$ ) did not reach statistical significant power output differences. However, the $140 \mathrm{rpm}$ showed statistically significantly $(p<0.05)$ reduced power output (peak $896.3 \pm 216.2 \mathrm{~W} ; 10 \mathrm{sec} 784.4 \pm 186.8 \mathrm{~W}$ ) compared to $100 \mathrm{rpm}$ and $120 \mathrm{rpm}$ tests. The groups average highest power output was achieved at cadences of $113.9 \pm 10.6 \mathrm{rpm}$ and highest 10 second power output at $111.7 \pm 11.9 \mathrm{rpm} .7$ cyclists achieved their best peak (and 9 best 10 seconds average) power in cadence $100 \mathrm{rpm}, 16$ (13) in cadence $120 \mathrm{rpm}$ and only 1 (2) in cadence $140 \mathrm{rpm}$. 
Comparison of U16 and U18 groups revealed statistically significant higher 10 second average power output in older group ( $944 \pm 184.8 \mathrm{~W}$ versus $791 \pm 147.1 \mathrm{~W}$ in M18 and M16 correspondingly, $p<0.05)$ as well as average cadence for generating above power output (117.1 $\pm 8.3 \mathrm{rpm}$ versus $106.3 \pm 12.8 \mathrm{rpm}$ in U18 and U16 correspondingly, $p<0.05)$. For peak power the values and corresponding cadence did not demonstrate statistically significant differences $(1089.6 \pm 227.7 \mathrm{~W}$ versus $908.8 \pm 206 \mathrm{~W}$ and for cadence $117.1 \pm 10.3 \mathrm{rpm}$ versus $110.8 \pm 10.3 \mathrm{rpm}$ for U18 and U16 correspondingly).

In U18 group was a mean peak and 10 seconds average power values of cadence $120 \mathrm{rpm}$ significantly higher than 100 and 140 rpm corresponding values. In U16 group was no significant differences between $100 \mathrm{rpm}$ and $120 \mathrm{rpm}$ power values but the $140 \mathrm{rpm}$ results showed statistically significantly $(p<0.05)$ reduced power output (Figure 1).

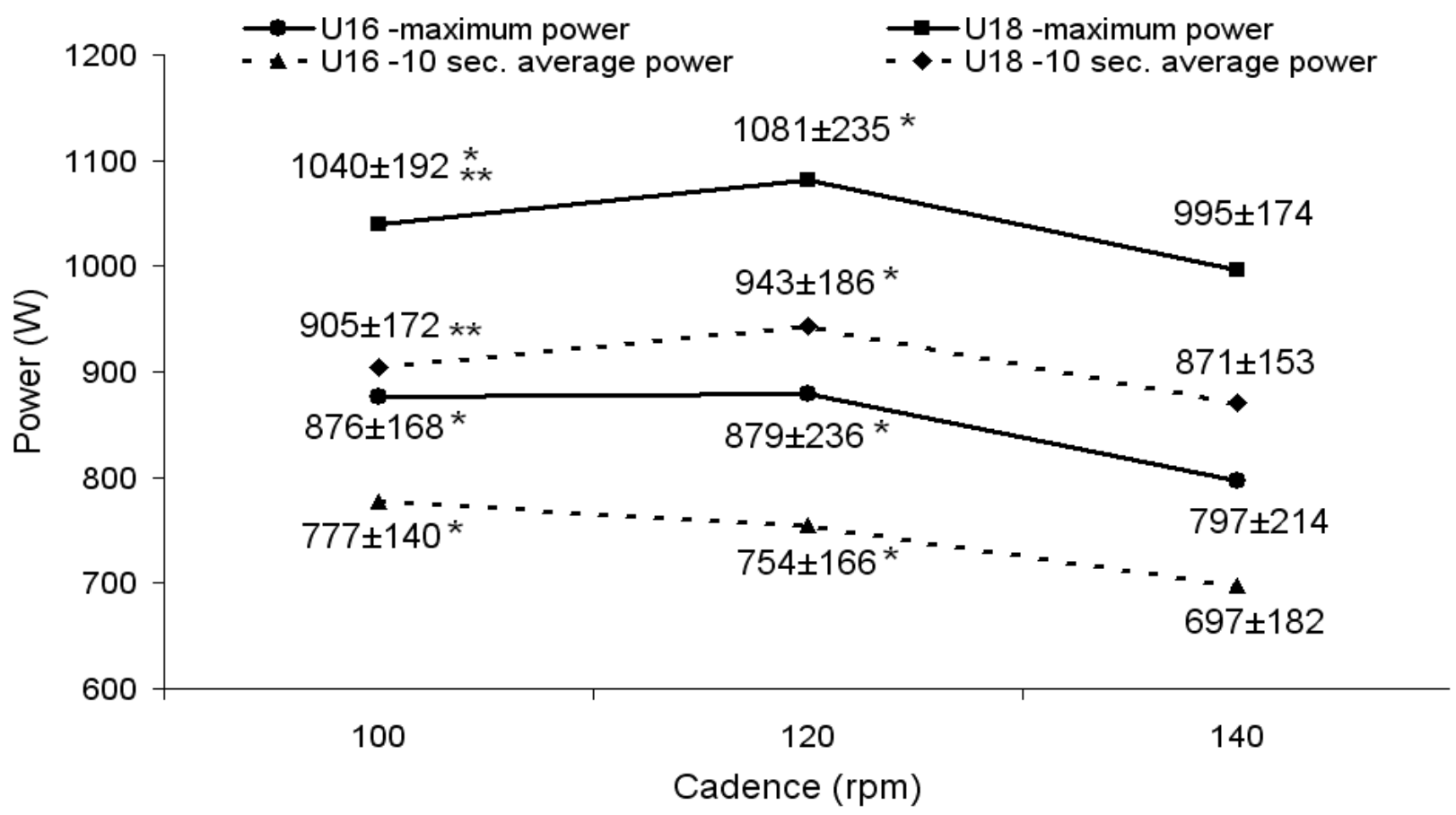

Figure 1. Comparison of power results in different cadences between U16 and U18 groups ( ${ }^{*}$-significant $(p<0,05)$ difference with $140 \mathrm{rpm}$ values, ${ }^{* *}$ - significant $(p<0,05)$ difference with $120 \mathrm{rpm}$ values).

The age of cyclists and most effectual cadences to achieve peak $(r=0.46)$ and 10 seconds average $(r=0.49)$ power were moderately correlated $(p<0.05)$. The subjects best power results were also positively $(r=0.55)$ correlated with the effectual cadence values $(p<0.01)$. 


\section{DISCUSSION}

Junior and youth national team road cyclists demonstrated effectual cadence at the point of maximal power generation (group average $113.9 \pm 10.6 \mathrm{rpm}$ ) that is similar to the values of professional road cyclist during the last $200 \mathrm{~m}$ sprinting to finish where 10 second average cadence is $109.9 \pm 5.3 \mathrm{rpm}$ and the highest average cadence is $117.6 \pm 6.1 \mathrm{rpm}$. The group average results of effectual cadence are lower than $120 \mathrm{rpm}$ that suggest van Soest and Casius (2000) for maximizing short time power, but most of (16) young cyclist achieve their best power in cadence $120 \mathrm{rpm}$. Our findings are similar to Zoladz et al. (2000) results - they found that healthy physically active males have higher $10 \mathrm{~s}$ sprint power values in pedaling rates $100 \mathrm{rpm}$ and $120 \mathrm{rpm}$.

Due to allowed gear choice the U16 class cyclists must exercise and compete with much higher cadence than U18 or adult class cyclists. Paradoxically younger cyclists (U16) had tendency to have lower effectual cadence than in older (U18) cyclists (average cadence for generating best 10 seconds power output were $106.3 \pm 12.8 \mathrm{rpm}$ versus $117.1 \pm 8.3 \mathrm{rpm}$ correspondingly and correlation's between age and effectual cadence were $r=0.46$ (peak power) and $r=0.49$ (10seconds average power), $p<0.05$ ). It appears that effectual cadence depends more on maturation and physiological condition (strong positive correlation between effectual cadence and maximal power value, $r=0.55, p<0.01$ ), than a regular cycling with higher cadence. These results confirm assumption that a fundamental muscle properties are determining the energetic of pedaling more than experience or training history (Umberger et al., 2006; Hansen et al., 2002; Hintzy et al., 1999).

\section{CONCLUSIONS}

The premise that regular work at high cadence regime due to limited transmission in youth category riders reflects in effectual cadence at the point of maximal power generation during the 10 second sprint effort was not corroborated.

\section{REFERENCES}

1. AHLQUIST LE, BASSETT DR JR, SUFIT R, NAGLE FJ, THOMAS DP. The effect of pedaling frequency on glycogen depletion rates in type I and type II quadriceps muscle fibers during submaximal cycling exercise. Eur J Appl Physiol Occup Physiol. 1992; 65(4):360-364.

2. COAST JR \& WELCH HG. Linear increase in optimal pedal rate with increased power output in cycle ergometry. Eur J Appl Physiol Occup Physiol. 1985; 53(4):339-342.

3. DORELI S, HAUTIER CA, RAMBAUD O, ROUFFET D, VAN PRAAGH E, LACOUR JR, BOURDIN $M$. Torque and power-velocity relationships in cycling: relevance to track sprint performance in world-class cyclists. Int J Sports Med. 2005; 26(9):739-746.

4. FARIA I, SJOJAARD G, BONDE-PETERSEN F. Oxygen cost during different pedalling speeds for constant power output. J Sports Med Phys Fitness. 1982; 22(3):295-299.

5. GARDNER AS, MARTIN JC, MARTIN DT, BARRAS M, JENKINS DG. Maximal torque- and powerpedaling rate relationships for elite sprint cyclists in laboratory and field tests. Eur J Appl Physiol. 2007; 101(3):287-292.

6. HANSEN EA, ANDERSEN JL, NIELSEN JS, SJØGAARD G. Muscle fibre type, efficiency and mechanical optima affect freely chosen pedal rate during cycling. Acta Physiol Scand. 2002; 176(3):185 194. 
7. HINTZY F, BELLI A, GRAPPE F, ROUILLON JD. Optimal pedalling velocity characteristics during maximal and submaximal cycling in humans. Eur J Appl Physiol. 1999; 79:426-432.

8. MARSH AP \& MARTIN EP. The association between cycling experience and preferred and most economical cadences. Med Sci Sports Exerc. 1993; 25(11):1269-1274.

9. NERPTUNE RR, HULL ML. A theoretical analysis of preferred pedaling rate selection in endurance cycling. J Biomech. 1999; 32(4):409-415.

10. UMBERGER BR, GERRITSEN KG, MARTIN PE. Muscle fiber type effects on energetically optimal cadences in cycling. J Biomech. 2006; 39(8):1472-9.

11. VAN SOEST O, CASIUS LJ. Which factors determine the optimal pedaling rate in sprint cycling? Med Sci Sports Exerc. 2000; 32(11):1927-1934.

12. ZOLADZ JA, RADEMAKER AC, SARGEANT AJ. Human muscle power generating capability during cycling at different pedalling rates. Exp Physiol. 2000; 85(1):117-24. 